equipment checked prior to the event. Similarly, the above clauses can be adapted to existing consent forms for surgery to remind patients that they are undergoing surgery voluntarily, and surgery is never risk-free. As long as all parties and equipment involved in the surgery are qualified and safety procedures are followed, barring significant deviation from normal surgical procedures, surgeons and health trusts would, in our opinion, have a stronger legal standpoint. We must stress that this does not take away a patient's right to litigation in cases of negligence or incompetence. It will at least discourage any opportunistic legal actions in which the aim is more likely to be financially motivated.

\section{AUTHOR'S RESPONSE 2}

\section{doi 10.1308/003588407X155635}

\section{ROBERT WHEELER}

Child Health Directorate, Wessex Regional Centre for Paediatric

Surgery, Southampton General Hospital, Southampton, UK

\section{CORRESPONDENCE TO}

Robert Wheeler, Consultant Paediatric and Neonatal Surgeon, Child Health Directorate, Wessex Regional Centre for Paediatric Surgery, G Level, East Wing, Mailpoint 44, Southampton General Hospital, Tremona Road, Southampton S016 6YD, UK

E: robert.wheeler@suht.swest.nhs.uk

Our society places great importance on a citizen's right of self-determination. One of the most obvious opportunities to exercise autonomy is when a person is able to make an informed choice concerning their medical treatment.

The legal doctrine of consent ensures that people are put into a position where they can make an informed choice. Choices can be informed only if the chooser has a clear and accurate understanding of what the 'procedure' entails, together with its benefits, risks, complications and alternatives.

In a bungee jump, the 'procedure' entails the opposition of gravity by an elastic band. The benefit is that the jumper may have enjoyed the experience. The risks include a rebound into the bridge from which he was suspended, or hitting the ground. The complications are, therefore, self-evident. Given the simplicity of both the procedure and its potential outcomes, there is unlikely to be a significant gap in the knowledge base between the jumper and the purveyor of the jump.

The bungee jump can be distinguished from the consent for surgery. The relationship between jumper and purveyor is quite different than between patient and surgeon. Additionally, there is significant inequality between the knowledge of the patient and surgeon, and the matters to be communicated and understood by the patient are infinitely more complex.
Unlike the jumper, the patient who consults a surgeon acquired their problem involuntarily, and it is one that may fundamentally affect their health. The problem may be serious, possibly endangering life. If he or she wishes to remain healthy, the patient must, therefore, acquiesce to surgery there is effectively no choice in the matter; however, the jumper can simply walk away, and decide upon an alternative entertainment. The inevitability of the need for treatment gives the surgeon a degree of control over the patient far removed from that enjoyed by a purveyor of bungee jumps, yet Fong and colleagues try and persuade us that we should act in the manner of the latter.

I am honestly unable to decide whether Fong and colleagues are simply pulling my leg. The point of my article was to point out that good consent is simply good medicine, and that the lawyers are merely peripheral players. Litigation is clearly deeply unpleasant, and something that all surgeons wish to avoid. But litigation is still only a sideshow; our main purpose is to treat our patients properly, and the law provides some, albeit incomplete, guidance on how this may be achieved.

The reader will decide whether I have over-reacted to Fong et al. If they were suggesting that it is acceptable merely to place a conditional offer in front of the patient in a take-it-or-leave-it manner, then I would strongly disagree. This is incompatible with our moral duty to do the best for our patients.

\section{COMMENTS ON}

\section{doi $10.1308 / 003588406 \times 114712$}

M Newey, M Clarke, T Green, C Kershaw, P Pathak. Nurse-led management of carpal tunnel syndrome: an audit of outcomes and impact on waiting times. Ann R Coll Surg Engl 2006; 88: 399-401

\section{COMMENT 1}

doi $10.1308 / 003588407 X 155644$

\section{Carpal tunnel syndrome}

FRANK D BURKE

Pulvertaft Hand Centre, Derbyshire Royal Infirmary, Derby, UK

\section{CORRESPONDENCE TO}

FD Burke, Professor of Hand Surgery, Pulvertaft Hand Centre, Derbyshire Royal Infirmary, London Road, Derby DE1 2QY, UK E: frank.burke@virgin.net

The authors' discussion touches on the matter of economic justification. They mention that when the project was set up the cost-effectiveness of the alteration in practice was not considered. Indeed, I recall when the Trent Regional Audit for Surgery of the Hand visited Leicester, the Orthopaedic Business 
Manager mentioning that no business case had ever been put forward for this alteration in clinical practice - a most unusual situation in contemporary practice.

Senior experienced nurse practitioners are hopefully paid a salary commensurate with their experience. When I visited Leicester, my impression was that three or perhaps four patients were admitted by the nurse practitioner and then went forward with surgery in each operating session. A reasonably experienced trainee surgeon in our unit would likely do seven cases during an operating session. It may be that the throughput per list in Leicester has risen since our visit. Have the authors any data to offer concerning relative costs between carpal tunnel decompression performed by surgeons and those performed by nurse practitioners?

\section{COMMENT 2}

\section{doi 10.1308/003588407X155653}

\section{Concerns}

\section{DAVID CLARKSON, JASON NEIL-DWYER}

Department of Plastic Surgery, Nottingham City Hospital, Nottingham, UK

\section{CORRESPONDENCE TO}

David Clarkson, Department of Plastic Surgery, Nottingham City Hospital, Hucknall Road, Nottingham NG5 1PB, UK T: +44 (0)115 969 1169; M: +44 (0)7919 816565;

E: davidjclarkson@hotmail.com

Effective innovative practice should always be welcomed and whilst we commend Newey et al. on the demonstrated benefits of a nurse-led carpal tunnel service, we have several concerns as to its advantage over standard practice and its wider impact on healthcare.

1. Evaluating the effectiveness of any medical intervention relies on adequate reporting of complications. The study suggests that some patients only had 2 weeks of clinical follow-up, which is not sufficient to comment on those complications that have a longer time course, such as incomplete resolution or recurrence of symptoms, or pillar pain. In addition, the lack of independent assessment of outcome at any stage potentially introduces considerable bias and we feel that both these issues would benefit from further consideration.

2. It is not clear from the study what other service responsibilities the nurse practitioner had over and above the carpal tunnel theatre and clinic sessions stated. As such, a true assessment of the cost-effectiveness and wider benefits to overall healthcare provision offered by employing a nurse practitioner to perform this procedure in preference to a surgical trainee cannot be fully appreciated.
3. Any service requires sustainability, which requires that there be a system in place for training replacement personnel. It is widely accepted that there are an everincreasing number of threats to training opportunities that have all significantly impacted on the experience of surgical trainees. Unfortunately, this system further erodes surgical exposure, de-skilling those who would be future trainers and contributing to a system that may ultimately prove unsustainable.

Some of the above issues were alluded to in the report and we agree that there are definite benefits to the implementation of a nurse-led service, as demonstrated in the study. However, the price we must pay for this may be unacceptably high in the longer term, and we feel very strongly that the overall impact on the provision of surgical services, if there was more widespread adoption of these schemes, has not been fully considered.

\section{AUTHOR'S RESPONSE}

doi 10.1308/003588407X155662

\section{MARTYN NEWEY}

Department of Orthopaedic Surgery, Leicester General Hospital, Leicester, UK

\section{CORRESPONDENCE TO}

M Newey, Consultant Orthopaedic Surgeon, Leicester General Hospital, Gwendolen Road, Leicester LE5 4PW, UK

E: martyn.newey@uhl-tr.nhs.uk

Professor Burke does not describe where the carpal tunnel procedures in his unit are performed. In our unit, these procedures are performed on an outpatient basis in a designated area separate from the main orthopaedic and day-case theatres. Our nurse operator performs about 5 cases per list with each list running from 8.30 am to about $11.00 \mathrm{am}$. The running costs including staff and disposable instruments are about $£ 50$ per half-hour compared to a standard theatre cost, which is about $£ 400$ per half-hour including staff and disposable usage.

The National Tariff (HRG) for carpal tunnel decompression is $\mathfrak{£ 6 9 5}$. If 7 carpal tunnel procedures are performed in a half-day list $(3.5 \mathrm{~h})$ using standard theatre facilities, the theatre costs will be $£ 2800$, while the procedures would generate $\mathfrak{£} 4865$, a net gain of $£ 2065$. In our unit, 5 procedures are performed in $2.5 \mathrm{~h}$ equating to $£ 250$ of theatre

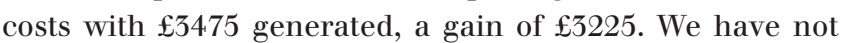
included day-ward costs (which we do not incur) or operator fees, be they for trainee surgeon or nurse operator.

Our service, therefore, provides considerable savings compared to procedures performed using normal day-case facilities and also frees up theatre space for more major 